\title{
Effect of Bubble CPAP in PTLBW Neonates with Respiratory Distress
}

\author{
Liton Chandra Saha*, Mak Azad Chowdhury, Md Mahbubul Hoque, Md. Abdulla Al Mamun and Maksudur \\ Rahman \\ Department of Neonatal Medicine, Bangladesh Institute of Child Health, Bangladesh
}

Submission: January 23, 2017; Published: February 21, 2017

*Corresponding author: Dr. Liton Chandra Saha, Assistant professor, Department of Neonatal Medicine, Bangladesh Institute of Child Health (BICH), Dhaka Shishu (Children) Hospital, Sher-e-Bangla Nagar, Dhaka-1207, Bangladesh, Email: sahaliton11@gmail.com

\begin{abstract}
Introduction: Bubble continuous positive airway pressure is a well-established modality for providing ventilator support to spontaneously breathing infants. It has been used in a variety of clinical situations.

Objectives: To evaluate the immediate outcome of PTLBW neonates with respiratory distress by using Bubble Continuous Positive Airway Pressure (BCPAP).

Materials and Methods: This Clinical Trial (Quasi-Experimental study) was conducted from 1st April 2013 to 30th September 2014 in the SCABU of Dhaka Shishu (Children) Hospital. Total 172 preterm babies with a gestational age $<35$ weeks, presented with clinical signs of respiratory distress were included in the study and among them 85 cases were taken as BCPAP group who were treated by bubble CPAP and 87patients who could not be treated by BCPAP due to unavailability of BCPAP machine at that time were taken as control. Effects of BCPAP were assessed by comparing the clinical conditions, oxygen saturation and arterial blood gas status. Written informed consent from guardian was taken.

Results: Mean gestational age, weight and age at the time of admission were comparable in two groups (BCPAP vs Control: GA $31 \pm 1.61$ vs $30 \pm 1.93$ weeks, birth weight $1454 \pm 284$ vs $1435 \pm 228 \mathrm{gm}$, age $28 \pm 13$ vs $31 \pm 19 \mathrm{hrs}$ ). It was found that duration of 02 need was significantly $(\mathrm{p}<0.05)$ less in BCPAP group than the control group ( $5.61 \pm 1.61$ vs8.49 \pm 3.22 days), significantly $(\mathrm{p}<0.05)$ less duration to improve respiratory distress ( $3.69 \pm 1.55$ vs $7.67 \pm 2.76$ days) and hospital stay ( $8.74 \pm 3.72$ vs $12.67 \pm 11.75$ days) was required in BCPAP group. Requirement of mechanical ventilation (IMV) was also less in BCPAP group $(27.06 \%$ vs $51.72 \%, \mathrm{P}<0.05)$.
\end{abstract}

Conclusion: This study found that CPAP is an effective modality of treatment of PTLBW neonates with respiratory distress.

Keywords: Bubble CPAP; PTLBW; Respiratory distress

Abbreviations: CPAP: Continuous Positive Airway Pressure; PTLBW: Preterm Low Birth Weight

\section{Introduction}

Globally about $17 \%$ of all infants that are born alive each year have a low birth weight (LBW), defined as a body weight of less than 2,500 gm at birth (WHO, 1980, 1984). The rate of preterm birth for infants with less than 37 weeks gestational age has been steadily increasing since 1990 and is now at $12.5 \%$ or 1 of every 8 live births in the United States.1 The proportion of low birthweight infants, those who weight less than $2500 \mathrm{gm}$, has increased from $7.9 \%$ in 2003 to $8.1 \%$ in 2004 [1]. Ninety percent (90\%) of these infants are born in developing countries. Low birth weight is considered a major public health problem in populations where the prevalence is greater than 15\% (ACC/SCN, 2000). Asia, and particularly South Asia, has a higher prevalence of LBW than any other continent in the world.
In South Asia, the prevalence ranges from $15 \%$ to $30 \%$ (UNICEF \& WHO, 2004). In Bangladesh, BBS/UNICEF country-wide survey in 2003-2004 revealed 36\% of newborns are LBW [2]. The survey confirms that low birth weight is a major public health problem in Bangladesh. In developing countries, an increasing proportion (41\%) of deaths of children less than 5 years of age occurs in the neonatal period [3]. There are lot of complications of preterm low birth weight (PTLBW) among them respiratory distress is most common. Respiratory distress occurs in $0.96-12 \%$ of life births and is responsible for about $20 \%$ of neonatal mortality [4]. It is the most common presenting problem of newborns encountered within the first 48-72 hours of life [4] and remains the primary indication for admission to Neonatal Intensive Care Unit to combat 
respiratory failure. For two decades, the standard treatment for very preterm infants was with assisted ventilation and surfactant. However, since ventilation may damage the lungs [5], it has been hypothesized that the avoidance of ventilation might lead to less morbidity and mortality. Nasal continuous positive airway pressure is a well-established modality for providing ventilatory support to spontaneously breathing infants. It has been used in a variety of clinical situations [6].

Nasal continuous positive airway pressure (NCPAP) is a modality that supports spontaneous ventilation by providing a positive airway pressure throughout the whole respiratory cycle [6]. CPAP is relatively inexpensive and can be easily taught, this could have the potential to be the optimal respiratory support device to implement in developing countries $[7,8]$. A wide variety of devices are used to deliver CPAP, including variable flow driver devices, single or binasal prongs where pressure is generated by a column of water (bubble CPAP) or a ventilator. Bubble CPAP (BCPAP) is appealing because of its simplicity and low cost. With this technique gas flows past the nasal device and the pressure is generated in the circuit by placing the distal limb of the CPAP circuit under a known depth of water that creates bubbles and pressure oscillations in the circuit [9]. Gas flow is increased until continuous bubbling is achieved.

It has been suggested that use of BCPAP in the poorly compliant lung may promote lung volume recruitment and augment the efficiency of gas mixing. CPAP delivered by underwater seal causes vibration of the chest due to gas flow under water; and these vibrations simulate waveforms produced by high frequency ventilation. Lee, et al. [10] demonstrated the superiority of bubble CPAP as compared to ventilator derived CPAP in premature infants. Bubble CPAP is also a less expensive method of respiratory support, most suitable to neonatal units with limited resources in developing countries [11].

Continuous positive airway pressure (CPAP), when applied to premature infants with Respiratory distress syndrome (RDS), re-expands collapsed alveoli, splints the airway, reduces work of breathing and improves the pattern and regularity of respiration [12]. Atelecto-trauma (repeated opening and collapse of the alveoli), biotrauma (intubation of the airway) and volutrauma (overstretching of the alveoli), the key determinants of ventilator induced lung injury are minimal or absent in gentler modes of ventilation such as nasal CPAP $[13,14]$. Bubble CPAP, when used appropriately, is more cost effective, less intensive, requires less training and has lower risk of complications. We conducted this clinical trial to evaluate the immediate outcome of PTLBW neonate with respiratory distress on Bubble CPAP.

\section{Materials and Methods}

This Clinical Trial (Quasi-Experimental study) was conducted from 1st April 2013 to 30th September 2014 in the SCABU of Dhaka Shishu (Children) Hospital. Total 172 preterm low birth weight babies of less than 35 weeks gestation admitted within
72 hours of life with respiratory distress were included in the study. Among the 172 cases 85 were treated with BCPAP and rest 87 patients who treated conventionally due to unavailability of BCPAP machine at that time were taken as control. Patient with Gestational age $<35$ weeks admitted in the SCBU within 72 hours of life with respiratory distress were included. Babies requiring intubation at birth, severe peri natal asphyxia (APGAR $<3$ at 5 $\mathrm{min}$ ) and those with major malformation were excluded. If patient parents refuse to continue treatment or patient was referred to other hospital due to unavailability of mechanical ventilation were also excluded from the study. Respiratory distress was documented by Fast breathing (R/R- $>60 / \mathrm{min}$ ) and any one of the followings: Low $\mathrm{O}_{2}$ saturation $(<87 \%)$, Retraction, Grunting, Nasal flaring and Severe chest in drawing. If the parents refused to give consent, were not included in the study. Eligible babies were started on Bubble CPAP with bi-nasal prongs (Fisher and Paykel Healthcare). PEEP was started at $5 \mathrm{~cm}$ of water and adjusted to minimize chest retractions. $\mathrm{FiO}_{2}$ was adjusted to maintain $\mathrm{SpO} 2$ between $87 \%$ and $95 \%$. Flow was titrated to the minimum to produce continuous bubbling in the bubble chamber.

Bubble CPAP was considered to be successful if the respiratory distress improved and the baby could be successfully weaned off from CPAP. The criteria for weaning was absence of respiratory distress (minimal or no retractions and respiratory rate between 30 and 60 per minute) and SpO $2>90 \%$ on $\mathrm{FiO} 2<30 \%$ and PEEP $<5$ $\mathrm{cm}$ of water. Infants were diagnosed to have failed CPAP and were started on mechanical ventilation when they:

A.remained hypoxic, i.e. $\mathrm{SpO}_{2}<87 \%$ despite $\mathrm{FiO}_{2}>70 \%$ and PEEP $>7 \mathrm{~cm}$ of water;

B.had severe retractions on PEEP $>7 \mathrm{~cm}$ of water;

C.had prolonged ( $>20$ seconds) or recurrent apneas ( $>2$ episodes within 24 hours associated with bradycardia) requiring bag and mask ventilation;

D.had severe metabolic acidosis or shock requiring ionotropic support (dopamine and or dobutamine) $>20 \mu \mathrm{g} / \mathrm{kg} / \mathrm{min}$.

Infants failing CPAP in the first 1 week of life were considered to be CPAP failures. Data collection of maternal variables included multiple births, pregnancy induced hypertension, preterm premature rupture of membrane, cesarean section and antenatal steroids. Gestational age was calculated based on mother's last menstrual period and or early pregnancy ultrasound scan or New Ballard score. Infant variables evaluated included birth weight, gestational age, Apgar score at 1 minute, delivery room management (oxygen, bag and mask, intubation), X-ray chest, arterial blood gas and $\mathrm{FiO} 2$ requirement.

The other clinical data recorded are patent ductus arteriosus (PDA) (clinical and Echo proven), pneumothorax, culture positive sepsis, pneumonia, necrotizing enterocolitis (NEC), chronic lung disease (oxygen requirement at 36 weeks PMA), germinal matrix - intraventricular hemorrhage (IVH), periventricular leucomalacia 
(PVL) (neurosonogram before day 7, at discharge and at 40 weeks PMA), retinopathy of prematurity (ROP) of any grade, duration of hospital stay among the survivors, and mortality. The study assessed the following outcomes: Duration of $\mathrm{O}_{2}$ need, duration to improve respiratory distress, need for mechanical ventilation, duration of hospital stay, survive and discharge. Data were analyzed with the use of the Statistical Package for Social Science program (SPSS version 15.0). Data was compared between CPAP group with control group. The independent samples t-test was used for group comparisons of normally distributed variables. For comparisons of categorical data we used the Chi-square test. Statistical significance was determined at $\mathrm{P}$ value $<0.05$. The study was approved by the institute ethics committee and informed consent was obtained from either the father or a guardian.

\section{Results}

Table 1: Baseline characteristics of neonates in both BCPAP and control groups $(n=172)$.

\begin{tabular}{|c|c|c|c|}
\hline Baseline Characteristics & $\begin{array}{c}\text { BCPAP } \\
\text { Group }(\mathrm{N}=85) \\
(\text { mean } \pm \mathrm{s} d)\end{array}$ & $\begin{array}{c}\text { Control } \\
\text { Group }(\mathrm{N}=87) \\
(\text { mean } \pm \mathrm{s} d)\end{array}$ & $\mathrm{P}^{*}$ value \\
\hline Age on admission in Hours & $28 \pm 13$ & $31 \pm 19$ & 0.24 \\
\hline Weight on admission in gm & $1454 \pm 284$ & $1435 \pm 228$ & 0.62 \\
\hline Gestational age in wks & $31 \pm 1.61$ & $30 \pm 1.93$ & 0.15 \\
\hline respiratory rate & $70.87 \pm 6.05$ & $70.10 \pm 2.76$ & 0.28 \\
\hline Grunting [N (\%)] & $52(61 \%)$ & $51(59 \%)$ & $0.42^{* *}$ \\
\hline Chest indrawing [N (\%)] & $50(58 \%)$ & $49(56 \%)$ & $0.76^{* *}$ \\
\hline Oxigen saturation $(\%)$ & $83.09 \pm 4.84$ & $82.37 \pm 6.62$ & 0.41 \\
\hline $\mathrm{PH}$ & $7.20 \pm 0.05$ & $7.18 \pm 0.07$ & 0.08 \\
\hline $\mathrm{PCO} 2$ & $31.38 \pm 8.72$ & $31.11 \pm 8.79$ & 0.84 \\
\hline PO2 & $45.89 \pm 12.87$ & $46.28 \pm 12.42$ & 0.85 \\
\hline $\mathrm{HCO} 3$ & $15.14 \pm 4.44$ & $15.03 \pm 4.43$ & 0.86 \\
\hline $\mathrm{BE}$ & $-10.49 \pm 4.27$ & $-10.57 \pm 4.25$ & 0.90 \\
\hline
\end{tabular}

Total 172 preterm low birth weight babies of less than 35 weeks gestation admitted within 72 hours of life with respiratory distress were included in the study. Among the 172 cases 85 were treated with BCPAP and rest 87 patients who treated conventionally due to unavailability of BCPAP machine at that time were taken as control. Mean gestational age, weight and age at the time of admission were comparable in two groups (BCPAP vs Control: GA $31 \pm 1.61$ vs $30 \pm 1.93$ weeks, birth weight $1454 \pm 284$ vs $1435 \pm 228$ gm, time $28 \pm 13$ vs $31 \pm 19 \mathrm{hrs}$ ) (Table 1 ). Respiratory parameters like respiratory rate, chest indrawing, grunting and oxygen saturation were also comparable in both groups (R/R$70.87 \pm 6.05$ vs $70.10 \pm 2.76$, Gr-52 (61\%) vs 51 (59\%), C/I- $50(58 \%)$ vs $49(56 \%)$ and 02 sat $-83.09 \pm 4.84$ vs $82.37 \pm 6.62$ ) (Table 1 ). Diagnosis of enrolled patients was RDS, PNA, TTN, Pneumonia and MAS and these were similar in both groups (Figure 1).

Table 2: Comparison of blood gas changes at different time point between both BCPAP and control groups (n=172).

\begin{tabular}{|c|c|c|c|c|}
\hline \multirow{2}{*}{ Blood Gas } & Duration & $\begin{array}{c}\text { BCPAP } \\
\text { Group (N=85) } \\
\text { (mean } \pm \mathbf{s ~ d )}\end{array}$ & $\begin{array}{c}\text { Control } \\
\text { Group (N=87) } \\
\text { (mean } \pm \mathbf{s ~ d ) ~}\end{array}$ & P* value \\
\hline \multirow{2}{*}{ PH } & Before intervention & $7.20 \pm 0.05$ & $7.18 \pm 0.07$ & 0.08 \\
\cline { 2 - 5 } & At 48 hrs of intervention & $7.371 \pm 0.05$ & $7.20 \pm 0.12$ & 0.00 \\
\hline \multirow{2}{*}{ PCO2 } & Before intervention & $31.38 \pm 8.72$ & $31.11 \pm 8.79$ & 0.84 \\
\cline { 2 - 5 } & At 48 hrs of intervention & $46.18 \pm 6.26$ & $47.62 \pm 9.22$ & 0.23 \\
\hline \multirow{2}{*}{ PO2 } & Before intervention & $45.89 \pm 12.87$ & $46.28 \pm 12.42$ & 0.85 \\
\cline { 2 - 5 } & At 48 hrs of intervention & $86.06 \pm 38.24$ & $46.86 \pm 7.47$ & 0.00 \\
\hline
\end{tabular}




\section{Academic Journal of Pediatrics \& Neonatology}

\begin{tabular}{|c|c|c|c|c|}
\hline \multirow{2}{*}{$\mathrm{HCO} 3$} & Before intervention & $15.14 \pm 4.44$ & $15.03 \pm 4.43$ & 0.86 \\
\cline { 2 - 5 } & At 48 hrs of intervention & $18.64 \pm 3.75$ & $15.50 \pm 3.39$ & 0.00 \\
\hline \multirow{2}{*}{$\mathrm{BE}$} & Before intervention & $-10.49 \pm 4.27$ & $-10.57 \pm 4.25$ & 0.90 \\
\cline { 2 - 5 } & At 48 hrs of intervention & $-7.41 \pm 6.62$ & $-12.12 \pm 6.82$ & 0.00 \\
\hline
\end{tabular}

There was significant $(\mathrm{p}<0.05)$ changes in arterial blood gas status in BCPAP group but not in control group (Table 2). There was significant $(\mathrm{p}<0.05)$ improvement of respiratory status i.e. decrease in respiratory rate (RR- $70.87 \pm 6.05$ to $47.96 \pm 5.33$ ) and increase oxygen saturation (Sp02-83.09 \pm 4.84 to $94.24 \pm 4.97$ ) at 48 hours after BCPAP intervention but no significant ( $p>0.05$ ) changes in control group (Table 3 ). It was found that duration of 02 need was significantly $(\mathrm{p}<0.05)$ less in BCPAP group than Table 3: Comparison of clinical changes at different time point between both

\begin{tabular}{|c|c|c|c|c|}
\hline $\begin{array}{c}\text { Respiratory } \\
\text { Characteristics }\end{array}$ & Duration & $\begin{array}{c}\text { BCPAP } \\
\text { Group }(N=85) \\
(\text { mean } \pm s d)\end{array}$ & $\begin{array}{c}\text { Control } \\
\text { Group }(\mathrm{N}=87) \\
(\text { mean } \pm s d)\end{array}$ & $P^{*}$ value \\
\hline \multirow{2}{*}{$\begin{array}{l}\text { Respiratory rate } \\
\text { (mean } \pm \mathrm{s} \text { d) }\end{array}$} & Before intervention & $70.87 \pm 6.05$ & $70.10 \pm 2.76$ & 0.28 \\
\hline & At $48 \mathrm{hrs}$ of intervention & $47.96 \pm 5.33$ & $69.09 \pm 1.80$ & 0.00 \\
\hline \multirow{2}{*}{$\begin{array}{l}\text { Grunting } \\
{[\mathrm{N}(\%)]}\end{array}$} & Before intervention & $52(61 \%)$ & $51(59 \%)$ & $0.42^{* *}$ \\
\hline & At $48 \mathrm{hrs}$ of intervention & $08(9 \%)$ & $43(49 \%)$ & $0.00^{* *}$ \\
\hline \multirow{2}{*}{$\begin{array}{c}\text { Chest in drawing } \\
{[\mathrm{N}(\%)]}\end{array}$} & Before intervention & $50(58 \%)$ & $49(56 \%)$ & $0.76^{* *}$ \\
\hline & At $48 \mathrm{hrs}$ of intervention & $18(21 \%)$ & $47(54 \%)$ & $0.00^{* *}$ \\
\hline \multirow{2}{*}{$\begin{array}{l}\text { 02 saturation } \\
\text { (mean } \pm \mathrm{s} d)\end{array}$} & Before intervention & $83.09 \pm 4.84$ & $82.37 \pm 6.62$ & 0.41 \\
\hline & At $48 \mathrm{hrs}$ of intervention & $94.24 \pm 4.97$ & $83.37 \pm 6.77$ & 0.00 \\
\hline
\end{tabular}

Table 4: Comparison of outcome in both BCPAP and control groups $(n=172)$.

\begin{tabular}{|c|c|c|c|}
\hline Outcome & $\begin{array}{c}\text { BCPAP } \\
\text { Group (N=85) } \\
\text { (mean } \pm \mathbf{s ~ d ) ~}\end{array}$ & $\begin{array}{c}\text { Control } \\
\text { Group (N=87) } \\
\text { (mean } \pm \mathbf{s ~ d )}\end{array}$ & $\mathbf{P}^{*}$ value \\
\hline $\begin{array}{c}\text { Duration of 02 need in days } \\
\text { Duration to improve respiratory } \\
\text { distress in Days }\end{array}$ & $5.61 \pm 1.61$ & $8.49 \pm 3.22$ & 0.00 \\
\hline Hospital stay in days & $3.69 \pm 1.55$ & $7.67 \pm 2.76$ & 0.00 \\
\hline $\begin{array}{c}\text { Need for Mechanical ventilation } \\
{[\mathrm{N}(\%)]}\end{array}$ & $8.74 \pm 3.72$ & $45(51.72 \%)$ & 0.00 \\
\hline Survived and discharged [N (\%)] & $65(27.06 \%)$ & $42(48.28 \%)$ & 0.00 \\
\hline
\end{tabular}

\section{Discussion}

Role of CPAP in preterm and low birth weight infants is well documented $[15,16]$. CPAP has been used primarily to treat surfactant deficiency in preterm infants for many years [17]. Particular interests in CPAP focuses on its potential role to reduce ventilator induced lung injury. One postulated mechanism is the avoidance of aggressive initiation of intermittent positive pressure ventilation with high tidal volumes and inadvertent hyperventilation or under ventilation that occurs in ventilated infants [18]. CPAP also protects the airway from mechanical injury and bacterial colonization related to the endo tracheal tube. CPAP putatively increases both functional residual capacity and endogenous respiratory drive leading to decreased delivery room intubations, re intubations and days on mechanical ventilation $[18,19]$. In addition; CPAP reduces the expression of superoxide

the control group $(5.61 \pm 1.61$ vs $8.49 \pm 3.22$ days $)$, significantly $(\mathrm{p}<0.05)$ less duration to improve respiratory distress $(3.69 \pm 1.55$ vs $7.67 \pm 2.76$ days $)$ and hospital stay $(8.74 \pm 3.72$ vs $12.67 \pm 11.75$ days) was required in BCPAP group. Requirement of mechanical ventilation (IMV) was also less in BCPAP group $(27.06 \% \%$ vs $51.72 \% \%, \mathrm{P}<0.05$ ) (Table 4). It also showed that survived and discharged in BCPAP group was 65 (76.47\%) and was statistically

significant $(\mathrm{P}<0.05)$ (Table 4$)$.

BCPAP and control groups $(n=172)$ 
CPAP was 23.5 hours (range 2 -144 h). In a study by Courtney SE, [22] the birth weight was (mean \pm sd) $1081 \pm 316 \mathrm{~g}$, gestational age $29 \pm 2$ weeks, age at study $13 \pm 12$ days and they did not shown the duration of CPAP.

In this study there was significant $(p<0.05)$ decrease in respiratory rate, increase in 02 saturation and also significant $(p<0.05)$ changes in arterial blood gas analysis after BCPAP intervention i.e, increased pH, PO2, HCO3 and BE but no changes observed in control group. There was significant $(\mathrm{p}<0.05)$ change in duration of 02 need $(5.61 \pm 1.61$ vs. $8.49 \pm 3.22$ days) and duration to improve respiratory distress $(3.69 \pm 1.55$ vs. $7.67 \pm 2.76$ days). Mean duration of hospital stay was higher in neonates who were in control group (12.67 \pm 11.75 days) where as in BCPAP group it was $8.74 \pm 3.72$ days. It also showed $65(76.47 \%)$ of neonates who received bubble CPAP and 42 (48.28\%) neonates in control group survived and the difference was found statistically significant $(\mathrm{P}<0.05)$. In the study by Koti et al. [21] in infants surviving till discharge, the median duration of oxygen requirement was 102 (range 13-504 h) and median duration of hospital stay was 11 days (range 3-37 days). No baby had chronic lung disease. They did not show the blood gas analysis, respiratory rate and oxygen saturation changes in their study. In a study by De Klerk et al. [15], they had shown CPAP in preterm infants decrease the median duration of oxygen requirement (4 days) and median duration of hospital stay (6 days). They also found CPAP treatment decrease respiratory and some non-respiratory adverse outcomes.

In this study $27 \%$ of babies started on Bubble CPAP required ventilation whereas in control group it was $51 \%$. No baby required oxygen for more than 28 days. Only one babies had pneumothorax but that baby was stabilized on Bubble CPAP and required neither ventilation nor chest tube drainage. In the study by Koti et al. [21] $25 \%$ of babies started on Bubble CPAP required ventilation. They found only two babies had pneumothorax but both these babies were stabilized on Bubble CPAP and required neither ventilation nor chest tube drainage. Lanieta et al. [7] had shown the introduction of BCPAP was associated with the reduction in the need for mechanical ventilation and also decreased case fatality.

In a retrospective study by Ammari et al. [23] the failure rate of Bubble CPAP was $24 \%$ in babies' $\leq 1250 \mathrm{~g}$ and $50 \%$ in babies $\leq 750 \mathrm{~g}$. None of the babies with gestation $>30$ weeks failed CPAP. The main difference between our study and that by Ammari et al. [23] are:

A.ours is a unit which is doing Bubble CPAP for respiratory distress for 8 months before the onset of the study

B.we used Fisher and Paykel nasal prongs [23] was used in this study while it was Hudson prongs in their study

C.definition of CPAP failure included $\mathrm{FiO}_{2}>70 \%$ and PEEP $>7 \mathrm{~cm}$ for the first 7 days of life as against $\mathrm{FiO} 2>60 \%$ for the first 72 hours of life. No PEEP criteria were set in their study. These major differences might explain the differences in failure rates in the two studies. Since most events in the early neonatal period are reflections of the care and support in the first couple of days, we choose 7 days as the cut off for CPAP failures.

Establishing a NICU with mechanical ventilation would require high level of expertise and trained personnel, which is far from reality in many of the peripheral and district hospitals in developing countries. Lanieta et al. [7] have successfully demonstrated the usefulness of BCPAP in a developing country, and have also reported the cost effectiveness with use of Bubble CPAP [7]. Pieper et al. [8] have shown the importance of CPAP in the absence of neonatal intensive care and also the improved outcome in neonates treated with CPAP prior to transfer to a tertiary unit. Bubble CPAP, thus, may be considered as a primary mode of respiratory support in resource poor settings.

\section{Conclusion}

It is concluded from this study that Bubble CPAP is an effective way of improving oxygenation (e.g: 02 saturation and $\mathrm{P}^{\mathrm{H}}, \mathrm{PCO}_{2}$, $\mathrm{PO}_{2}$ and $\mathrm{BE}$ ) of preterm LBW babies with respiratory distress due to various causes. BCPAP use can reduces hospital stay and the need for mechanical ventilation.

\section{References}

1. Hamilton B, Martin J, Ventura S, Sutton P, Menacker F (2005) Division of Vital Statistics. Births: Preliminary Data for 2004. Atlanta 54(8).

2. Bangladesh Bureau of Statistics and UNICEF (2005) National Low Birth Weight Survey of Bangladesh, 2003-4. Dhaka/UNICEF.

3. Black RE, Cousens S, Johnson HL (2010) Global, regional, and national causes of child mortality in 2008: a systematic analysis. Lancet 375(9730): 1969-1987.

4. Neonatal morbidity and mortality (1997) Report of the National Neonatal Perinatal database. Indian Pediatr 34(11): 1039-1042.

5. Jobe AH, Bancalari E (2001) Broncho pulmonary dysplasia. Am J Respir Crit Care Med 163(7): 1723-1729.

6. I U Cheema, J S Ahluwalia (2003) The rational use of nasal continuous positive airway pressure. Current Paediatrics 13(3): 190 -195.

7. Koyamaibole L, Kado J, Qovu J, Colquhoun S, Duke T (2006) An evaluation of bubble-CPAP in a neonatal unit in a developing country: effective respiratory support that can be applied by nurses. J Trop Pediatr 52(4): 249-253.

8. Pieper CH, Smith J, Maree D, Pohl FC (2003) Is nCPAP of value in extreme preterms with no access to neonatal intensive care? J Trop Pediatr 49(3): 148-152.

9. C J Morley, R Lau, A De Paoli, P G Davis (2005) Nasal continuous positive airway pressure: does bubbling improve gas exchange? ADC Fetal Neonatal Edition 90(4): 343-344.

10. Boo NY, Zuraidah AL, Lim NL, Zulfiqar MA (2000) Predictors of failure of nasal continuous positive airway pressure in treatment of preterm infants with respiratory distress syndrome. J Trop Pediatr 46(3): 172175 .

11. Carlos JS (2006) Diagnostic imaging, In: Martin RJ, Fanaroff AA, et al. (Eds.), Neonatal- Perinatal Medicine: Diseases of the Fetus and Infant. (8th edn), Philadelphia: Mosby Elsevier Publishers, pp. 713-714.

12. Van Marter LJ, Allred EN, Pagano M, Sanocka U, Parad R, et al. (2000) Do clinical markers of barotraumas and oxygen toxicity 
explain interhospital variation in rates of chronic lung disease? The Neonatology Committee for the Developmental Network. Pediatrics 105(6): 1194-1201.

13. Attar MA, Donn SM (2002) Mechanisms of ventilator induced lung injury in premature infants. Semin Neonatol 7(5): 353-360.

14. Jobe AH, Kramer BW, Moss TJ, Newnham JP, Ikegami M (2002) Decreased indicators of lung injury with continuous positive expiratory pressure in preterm lambs. Pediatr Res 52: 387-392.

15. De Klerk A, De Klerk R (2001) Nasal continuous positive airway pressure and outcomes of preterm infants. J Paediatr Child Health 37:161-167.

16. Narendran V, Donovan E, Hoath S, Akinbi H, Steichen J, et al. (2003) Early bubble CPAP and outcomes in ELBW infants. J Perinatol 23: 195 199

17. Gregory GA, Kitterman JA, Phibbs RH, Tooley WH, Hamilton WK (1971) Treatment of the idiopathic respiratory distress syndrome with continuous positive airway pressure. N Engl J Med 284(24): 13331340 .
18. Ho JJ, Subramaniam P, Henderson-Smart DJ, Davis PG (2002) Continuous Distending Pressure for Respiratory Distress Syndrome in Preterm Infants. The Cochrane Library 2.

19. Davis PG, Henderson-Smart DJ (2002) Nasal continous positive airway pressure immediately after extubation for preventing morbidity in preterm infants. The Cochrane Library 92(2): 414-418.

20. H A Hady, B Shouman, H Aly (2011) Early weaning from CPAP to high flow nasal cannula in preterm infants is associated with prolonged oxygen requirement: A randomized controlled trial. Early Human Development 87(3): 205-208.

21. Koti J, Murki S, Gaddam P, Reddy A, Reddy MDR (2010) Bubble CPAP for respiratory distress syndrome in preterm infants. Indian Pediatr 47(2): 139-143.

22. Pandit PB, Courtney SE, Pyon KH, Saslow JG, Habin RH (2001) Work of breathing during constant- and variable-flow nasal continuous positive airway pressure in preterm neonates. Pediatrics 108(3): 682-685.

23. Ammari A, Suri M, Milisavljevic V (2005) Variables associated with the early failure of nasal CPAP in very low birth weight infants. J Pediatr 147(3): 341-347.

\section{Your next submission with Juniper Publishers will reach you the below assets}

- Quality Editorial service

- Swift Peer Review

- Reprints availability

- E-prints Service

- Manuscript Podcast for convenient understanding

- Global attainment for your research

- Manuscript accessibility in different formats

( Pdf, E-pub, Full Text, Audio)

- Unceasing customer service

Track the below URL for one-step submission https://juniperpublishers.com/online-submission.php 